\title{
La tramitación autónoma del procedimiento tributario sancionador en México, en el contexto del respeto al derecho humano a la seguridad jurídical
}

\author{
Alejandro Díaz Reyes ${ }^{2}$ \\ Gabriela Aguado Romero 3
}

1 El texto es resultado parcial de los proyectos de investigación denominados "Derechos humanos y potestad punitiva del Estado. El paradigma de la seguridad jurídica" y "Dogmática de los derechos humanos en México". Investigaciones realizadas por integrantes del Doctorado en Derecho de la Universidad Autónoma de Querétaro, México. Las investigaciones no cuentan con financiamiento y están en curso.

2 Licenciado en Derecho, con diplomado en Contribuciones Fiscales, especialista en Derecho Fiscal, Maestría en Impuestos y aspirante a doctor de la Universidad Autónoma de Querétaro (UAQ). Catedrático en Licenciatura y en la Maestría en Administración Pública Estatal y Municipal de la Facultad de Derecho, UAQ, Santiago de Querétaro, México. Ha fungido como catedrático en la Maestría en Impuestos en Posgrado de la Facultad de Contaduría y Administración, UAQ. Profesor investigador en la misma universidad. Abogado litigante en el área tributaria y administrativa, Santiago de Querétaro, México. Correo-e: alex-diaz-23@hotmail.com.

3 Licenciada en Derecho, con Especialidad en Derecho Fiscal y en Derecho Notarial, estudios de Maestría y Doctorado en Derecho por la Universidad Autónoma de Querétaro. Profesora investigadora de tiempo completo en la misma universidad, impartiendo cátedra en la Licenciatura en Derecho, en la Maestría y el Doctorado en Ciencias Jurídicas del Programa Nacional de Posgrados de Calidad (PNPC), Santiago de Querétaro, México. Cuenta con el reconocimiento Perfil Deseable Prodep dentro del Programa Nacional de Desarrollo Profesional Docente. Integrante del cuerpo académico consolidado "Derechos humanos y Globalización" CAC-128-FDEUAQ, Miembro del Sistema Nacional de Investigadores CONACYT, nivel candidato SNI. Correo-e: aguadogabriela@hotmail.com. Fecha de recepción: $1{ }^{\circ}$ de marzo de 2018. Fecha de modificación: 30 de abril de 2018. Fecha de aceptación: 10 de mayo de 2018. Para citar el artículo: Díaz Reyes, Alejandro y Aguado Romero, Gabriela, "La tramitación autónoma del procedimiento tributario sancionador en México, en el contexto del respeto al derecho humano de seguridad jurídica", Revista 


\section{RESUMEN}

Los deberes tributarios constituyen una auténtica necesidad pública que impone al Estado la adopción de una serie de procedimientos administrativos para realizar las actividades de fiscalización y sanción de su cumplimiento. Con el fin de asegurar el respeto del principio de seguridad jurídica y toda vez que los fines, las consecuencias jurídicas y los principios rectores de cada uno de estos procedimientos son diferentes, la presente investigación encuentra que estos deben adelantarse y resolverse de forma separada. Se argumenta por la separación del procedimiento administrativo sancionador en materia tributaria de otros procedimientos, como la visita domiciliaria, dentro del cual se encuentra inmerso, con el fin de proteger el derecho humano a la seguridad jurídica.

Palabras clave: Procedimiento administrativo, Seguridad jurídica, Procedimiento tributario sancionador, Sanción administrativa, Actividad de inspección.

\section{A Separate Adjudication Procedure for Fining Tax Violations in Mexico and the Respect of the Human Right of Legal Certainty}

\section{ABSTRACT}

Administrative procedures for tax supervision and for the fining of tax violations are essential to the State. In order to respect the human right of legal certainty and since the purposes, legal effects and principles governing administrative adjudication procedures can be different in tax supervision cases and those for fining tax violations, this paper argues in favor of separating both procedures under the Mexican tax legislation.

Keywords: Administrative Procedure, Legal Certainty, Procedure for Punishing Tax Violations, Administrative Punishing Measures, Tax Supervision.

\section{INTRODUCCIÓN}

En la problemática actual de escasez de recursos, el Estado implementa una serie de medidas para obtener ingresos preferentemente de fuentes tributarias. En este escenario, el cumplimiento puntual de los deberes tributarios se constituye en una auténtica necesidad pública, lo que obliga al Estado a instaurar 
una serie de actividades administrativas, como es la de fiscalización y la de sancionar los incumplimientos a las obligaciones tributarias. En el ejercicio de estas actividades, las autoridades administrativas competentes requieren adelantar una serie de procedimientos.

Pese a la necesidad del Estado de proteger el cumplimiento oportuno y cabal de los deberes tributarios a través de la puesta en marcha de procedimientos administrativos, no se debe olvidar que estas actuaciones persiguen fines diferentes $y$, por consiguiente, cada una de ellas produce consecuencias jurídicas distintas en cuanto a su naturaleza y se rigen por principios orientadores que les son propios.

De tal guisa, y dentro de un contexto de respeto irrestricto al derecho humano a la seguridad jurídica de los administrados, el ejercicio de la potestad sancionadora del Estado no puede estar supeditada y tramitarse dentro de un procedimiento administrativo como es el de visita domiciliaria, en el cual se desarrolla el ejercicio de la potestad fiscalizadora del Estado, por lo que este escrito argumenta que es obligatorio que se dé autonomía al procedimiento tributario sancionador respecto del procedimiento de fiscalización tributaria, esto es, que no se tramiten de forma unitaria.

En la presente investigación se plantea como objetivo un análisis acerca de la necesidad de autonomía en la instrucción y resolución del procedimiento tributario sancionador del procedimiento de visita domiciliaria en la legislación mexicana. De esta forma, el estudio inicia con el análisis del tributo como ingreso del Estado, lo cual comprende su potestad tributaria y el acto de determinación de la obligación fiscal, actuación que se materializa a través del procedimiento en el que la autoridad administrativa competente establece, en ejercicio de sus facultades de fiscalización, las cargas tributarias. Luego se pasa al examen de las consecuencias jurídicas que surgen ante el incumplimiento de la obligación de tributar, con especial atención a los principios que rigen la potestad sancionadora del Estado en materia tributaria y el procedimiento mediante el cual se materializa el ejercicio de esta potestad en la legislación tributaria mexicana. La investigación adelantada permite concluir que la tramitación unitaria de esos procedimientos administrativos vulnera el derecho humano a la seguridad jurídica del contribuyente.

\section{METODOLOGÍA}

Para estudiar el procedimiento administrativo de fiscalización y el tributario sancionador en México, en el contexto del respeto al derecho humano de seguridad jurídica, se hizo uso de una metodología de investigación cualitativa, con un paradigma epistemológico crítico. Para esto, se emplearon como técnicas de recolección de información la revisión documental contenida en diversas fuentes primarias, que se encuentra en informes gubernamentales acerca de la forma en la que se procede a la visita domiciliaria por parte de la 
autoridad tributaria, que permitió identificar temas específicos relevantes para el campo de la investigación. Como fuentes secundarias se exploró la doctrina especializada relacionada con el objeto de estudio, documentos obtenidos en bases de datos académicas, bibliografía y hemerografía.

Se hizo recurso a los métodos dogmático, deductivo, analítico y sintético, los cuales inducen a la utilización de la técnica de investigación documental. Fue necesario recurrir al método exegético en cuanto al uso de la legislación y la jurisprudencia.

Las fases metodológicas se comprendieron de una primera fase de recolección de información y su clasificación; una segunda fase fue el análisis de la anterior a través de la proyección metodológica que se asumió (determinar el respeto al derecho humano de seguridad jurídica en los procedimientos administrativo de fiscalización y el tributario sancionador), y una fase final de interpretación del análisis y construcción de conclusiones críticas respecto al aspecto jurídico que demanda el tema.

\section{EL TRIBUTO COMO INGRESO DEL ESTADO}

No hay duda en los innumerables referentes que han quedado plasmados a través de la historia, que el tributo es el más simbólico y fiel vestigio de los diversos gobiernos que han existido sobre la Tierra, por lo que en la actualidad "puede afirmarse que donde hay Estado hay tributo, es la sombra del Estado, el socio inexorable del ciudadano" ${ }^{\prime \prime}$.

De una revisión a la historia de la humanidad, es posible observar que se ha pretendido justificar las fuertes exigencias de tributar a través de diferentes formas, las cuales por mucho tiempo ignoraron la dignidad de los ciudadanos, siendo esto uno de los detonantes más comunes de las grandes revoluciones que han existido. Es posible citar, a manera de ejemplo, las revoluciones es tadounidense y francesa y la consecuente Declaración de los Derechos del Ciudadano $^{5}$, que a manera de protección hacia los ciudadanos respecto de las cargas tributarias, estableció límites y regulación de los excesos de la autoridad gobernante, de tal manera que en su artículo 13, se dispuso que "el mantenimiento de la fuerza pública y para los gastos de administración es indispensable una contribución común: debe ser igualmente repartida entre todos los ciudadanos en razón de sus posibilidades"; ${ }^{\prime}$ agregando luego en su artículo 14, que "todos los ciudadanos tienen el derecho de verificar por si mismos o por sus representantes las necesidades de la contribución pública, 
de aceptarla libremente, de vigilar su empleo y de determinar la cuota, la base la recaudación y la duración".

Estos hechos se corroboran en los diversos registros históricos, que documentan, por un lado, el excesivo e irracional requerimiento de pago de tributos a los gobernados, así como la lucha civil por limitar el poder tributario de los gobernantes; y por otro lado, resaltan el escaso trabajo de los historiadores y doctrinarios en cuanto al origen tributario de los derechos humanos, "han centrado sus estudios sobre el origen penal de los derechos humanos, apenas se ha comentado y documentado sobre el origen tributario de los mismos, siendo que una gran cantidad de movimientos revolucionarios alrededor del mundo comenzaron con la inconformidad de las acciones recaudatorias" ${ }^{\prime \prime}$. De tal suerte, que estos hechos históricos nos han cubierto de abundantes reseñas,

enseñanzas que demuestran el ocaso de grandes civilizaciones, en que se dieron las características de los excesivos requerimientos que aniquilaron las iniciativas tendientes al crecimiento de la riqueza, operándose la antítesis del Estado rico en pueblo pobre, que concluyó con la decadencia de los países que no opusieron adecuado límite a las exigencias fiscales ${ }^{7}$.

Ante este panorama, el tributo se erige como una fuente de ingresos ordinaria e imprescindible para los Estados modernos, donde el origen y cumplimiento de este deber se da con carácter de potestad pública, en razón de la responsabilidad que tiene el Estado de sufragar los gastos públicos, y con carácter de deber solidario, en virtud de las cantidades económicas que en su mayoría deben ser aportadas por los propios ciudadanos, sobre quienes recae el origen y fundamento de toda actividad estatal, "puesto que el bienestar de todos depende de un esquema de cooperación sin el cual ninguno podría llevar a cabo una vida satisfactoria, la división de ventajas debería ser tal que suscite la cooperación voluntaria de todos los que tomen parte en ella, incluyendo aquellos peor situados" ${ }^{\prime \prime}$.

Sin embargo, el establecimiento por parte del Estado de hechos imponibles en la ley, por medio de su potestad tributaria y el cumplimiento de estos deberes tributarios por parte de los ciudadanos, una vez actualizadas dichas hipótesis legales tributarias, se ven afectadas por ciertas complejidades de la vida actual, como son el crecimiento desmesurado de los aparatos burocráticos modernos, la baja en el poder adquisitivo de los ciudadanos, el desempleo, la

6 Juan Manuel Ortega Maldonado, Justicia tributaria y derechos bumanos, México: Instituto de Investigaciones Jurídicas de la Universidad Nacional Autónoma de México, 2016, p. 10. Disponible en línea https://archivos.juridicas.unam.mx/www/bjv/libros/9/4259/11.pdf.

7 JaCinto Tarantino R., Las penalidades tributarias, Buenos Aires: Editorial Astrea 1983, p. 2.

8 John Rawls, Teoría de la justicia, México: Editorial Fondo de Cultura Económica, 2015, p. 17. 
inflación, la corrupción y el aumento exorbitante de población, que se traduce en la demanda de más ingresos a causa de la demanda de satisfacción de necesidades cada vez más complejas.

Aunado a estas complejidades, respecto a la concepción de contribuir para el sostenimiento de los gastos públicos, en la actualidad permea un rechazo generalizado, "una conciencia social desfavorable en el sentido de que se percibe como una carga y durante largas épocas se ha sostenido el carácter odioso de las normas de carácter tributario" ${ }^{\prime \prime}$. Este sentido parte de la percepción que se tiene del deber de contribuir como una carga que nos impone el Estado, concepción que es incorrecta, ya que

la imposición de deberes a los ciudadanos ya no se debe fundar únicamente en el poder estatal, requiere de una legitimación superior. Y esta legitimación es la que le concede el fin con la que se establecen: el interés o el bien común. En aras de su consecución se reparten las cargas entre los ciudadanos de forma que solidariamente contribuyan al fin público ${ }^{10}$.

Los Estados, ante la imperiosa necesidad de obtención de este tipo de ingresos para poder costear los gastos públicos, se ven obligados a crear e implementar formas y procedimientos para fiscalizar a los contribuyentes, como es el procedimiento de visita domiciliaria, para comprobar el debido cumplimiento de los deberes tributarios por parte de los gobernados y poder determinar las correspondientes consecuencias jurídicas de naturaleza indemnizatoria. De igual manera, dentro del ámbito administrativo, a ejercer su ius puniedi implementando el procedimiento administrativo para sancionar punitivamente el incumplimientos de estos deberes tributarios.

Por ello, el sistema normativo del Estado no termina solo con establecer normas prescriptivas que regulen el comportamiento de los ciudadanos, sino que además se establecen normas y principios que limitan el actuar del Estado. Normas por las cuales se establecen instituciones, potestades y competencias; así como procedimientos a través de los cuales se ejercen las facultades, por lo que

el derecho no se agota en modo alguno en normas rectoras del comportamiento, sino que sirve a la organización y a la regulación y control del poder estatal. Funciona en el sentido de reglas constitutivas que no solamente garantizan la autonomía privada y pública, sino que genera instituciones estatales, procedimientos y competencias ${ }^{11}$.

9 Cristina Pauner Chulvi, El deber constitucional de contribuir al sostenimiento de los gastos públicos, Castellón: Universitat Jaume I, 2000, pp. 79-80. Disponible en línea http://www.tdx.cat/ bitstream/handle/10803/10429/pauner.pdf?sequence $=1$.

10 Ibíd., pp. 57-58.

11 Jürgen Habermas, Facticidad y validez, Madrid: Editorial Trotta, 2005, p. 212. 


\section{LA POTESTAD Y COMPETENCIA TRIBUTARIA DEL ESTADO Y SUS PRINCIPIOS RECTORES}

El Estado, al verse en la necesidad de obtención de recursos pecuniarios indispensables para el desarrollo de sus actividades, acude a fuentes de ingreso tributarias. Por este motivo se establece en la Constitución Política de los Estados Unidos Mexicanos la potestad tributaria, que le permite por vía legislativa "crear unilateralmente tributos cuyo pago será exigido a personas sometidas a su competencia tributaria espacial"12.

Sin embargo, la actividad del Estado en la obtención de recursos económicos para paliar el gasto público no puede agotarse solo en la creación de enunciados plasmados en ley de forma abstracta, debido a que al ser materializadas estas hipótesis normativas por un hecho fenoménico se generará el nacimiento de la obligación tributaria. De manera que es indispensable que el Estado cuente con otras facultades que permitan aplicar la ley tributaria sustantiva una vez actualizados los enunciados legales y estar en condiciones de verificar o constatar que se ha actualizado el hecho imponible, y por lo tanto el nacimiento de la obligación tributaria, y en consecuencia poder proceder a determinar la cuantía o extensión de la misma, para estar en condición de poder exigir, así como recaudar el ingreso tributario; todo ello a través de distintos procedimientos administrativos que se enmarcan dentro de la denominada competencia tributaria.

De tal suerte que tanto en la creación de los tributos como en su aplicación mediante los procedimientos que enmarcan la competencia tributaria, el Estado en todo momento, como lo corrobora Ortega ${ }^{13}$, se debe apegar a principios tributarios como el de proporcionalidad. Es decir, que deben ser congruentes con el principio de distribución de la carga tributaria y con la capacidad contributiva de cada sujeto pasivo. Por tanto, que estos procedimientos no sean confiscatorios y no representen un apoderamiento violento, y sin derecho por parte del Estado de la totalidad de los bienes del contribuyente; siendo en todo momento equitativos, donde se dé un trato idéntico o igualitario ante la misma ley tributaria a todos los sujetos pasivos que actualicen un mismo hecho imponible. Por lo que deben ser establecidos por el legislador en una ley en cumplimiento del principio de legalidad y reserva de la ley, en donde en la misma se establezcan los elementos esenciales del tributo, como son sujeto, objeto, base, tasa o tarifa, época de pago y las exenciones; donde se respete y aplique la ley tributaria que esté en vigor en el momento de actualización

12 Héctor B. Villegas, Curso de finanzas, derecho financiero y tributario, Buenos Aires: Ediciones Depalma, 2001, p. 186. Disponible en línea https://es.scribd.com/doc/50090118/VillegasHector-Curso-de-Finanzas-Derecho-Financiero-y-rio.

13 Juan Manuel Ortega Madonado, Primer curso de derecho tributario mexicano, México: Editorial Porrúa, 2004, pp. 203-254. 
del hecho imponible y no de forma retroactiva. De igual manera, es de suma importancia que se plasme el principio rector que establece que las cantidades que se obtengan por estas fuentes de ingreso tributarias serán destinadas a satisfacer el gasto público previsto en un presupuesto de egresos $;$, principios que limitan el ejercicio de la potestad y competencia tributaria del Estado.

\subsection{LAS FACULTADES FISCALIZADORAS EN EL EJERCICIO DE LA COMPETENCIA TRIBUTARIA ESTATAL}

El hecho imponible previsto en la ley es una hipótesis normativa abstracta, por lo que es de suma importancia primeramente verificar y calificar que el hecho fenoménico se encuadra en la hipótesis normativa, y verificar que se generó el nacimiento de la obligación de tributar. En segundo término, es de igual manera importante determinar el quantum o extensión de este deber sustantivo, que dará la cuantía monetaria que se deberá pagar por concepto de tributo; estos dos momentos constituyen el procedimiento de determinación tributaria, "conjunto de actos dirigidos a precisar, en cada caso particular, si existe una deuda tributaria an debeatur; en su caso, quién es el obligado a pagar el tributo al fisco (sujeto pasivo) y cuál es el importe de la deuda quantum debeatur"14.

En nuestro sistema legal tributario, corresponde el ejercicio inicial de este deber formal de autodeterminación tributaria al contribuyente, a la par o ante el incumplimiento de este deber por parte del sujeto pasivo,

las autoridades fiscales reservan en estos casos el derecho de ejercer sobre los obligados diferentes tipos de actos de control y revisión con el fin de verificar el grado de cumplimiento de esas obligaciones. La serie de actos establecidos para el control reciben el nombre de actos de inspección fiscal o actos de fiscalización ${ }^{15}$.

En el ejercicio de la potestad fiscalizadora, la autoridad tributaria cuenta con una amplia gama de facultades legales que le permiten llevar a cabo esta función, "cada uno de ellos sujeto a modalidades operativas distintas, pero todos al servicio de la detección del incumplimiento de las obligaciones tributarias y de la búsqueda de cambios en la conducta de los sujetos obligados" ${ }^{\prime \prime}$. Instrumentos que se desarrollan a través de procedimientos administrativos establecidos en la ley; en el caso de México, el legislador los regula el Código Fiscal de la Federación bajo la denominación de "facultades de comprobación", que tienen por finalidad "verificar si lo declarado por el contribuyente por concepto de contribuciones a su cargo son correctas o bien para cerciorarse

15 Doricela Mabarak Cerecedo, Derecho financiero público, México: Editorial McGraw Hill, 2007, p. 205.

16 Antonio JimÉnez González, Curso de derecho tributario, México: Taxx Editores, 2014, p. 377. 
del debido cumplimiento de todas las obligaciones a su cargo son satisfechas en los términos de la legislación tributaria en vigor ${ }^{\prime \prime}$. En otras palabras, el objeto de la fiscalización comprende la comprobación y la investigación, en la primera solo se busca constatar o corroborar la veracidad, cabalidad y la existencia de la información que ya conoce la Administración tributaria. En la segunda se encamina al descubrimiento de hechos y datos desconocidos por la autoridad tributaria.

Entre estos instrumentos de fiscalización, la "forma más enérgica y representativa de todos los actos de fiscalización lo constituye la visita domiciliaria"18, siendo esta facultad de fiscalización la más temida por los contribuyentes, "facultad de fiscalización más importante de las autoridades fiscales y que causa intranquilidad entre quienes la padecen, aun cuando cumplan correctamente con sus obligaciones fiscales" ${ }^{\prime \prime}$, lo anterior en virtud de que esta investigación y comprobación se realiza en el domicilio tributario del sujeto pasivo, y ello conlleva a una invasión o molestia en la esfera privada del particular.

Por consiguiente, el legislador además de otorgar esta potestad fiscalizadora a la autoridad, también debe regular su ejercicio mediante el establecimiento de procedimientos administrativos, para que se plasme de forma clara las formalidades y principios de naturaleza adjetiva que, además de limitar el actuar de la autoridad, le den certeza jurídica al sujeto pasivo de la relación tributaria.

\section{CONSECUENCIAS JURÍDICAS ANTE EL INCUMPLIMIENTO DEL DEBER TRIBUTARIO SUSTANTIVO}

Ante la actualización de un hecho imponible y la determinación de la obligación tributaria, lo procedente es su cumplimiento por parte del sujeto pasivo; sin embargo, ante el incumplimiento del deber tributario, entramos al campo del ilícito tributario, donde dicha conducta ilícita es calificada como infracción tributaria y como reproche jurídico acarrea una sanción. Es decir, una "consecuencia jurídica que el incumplimiento de un deber produce en relación con el obligado" ${ }^{\prime 2}$. Es preciso mencionar que en el ámbito tributario estas consecuencias jurídicas son de muy diversa naturaleza y con finalidades distintas. Referente a estas consecuencias jurídicas, en el presente artículo

17 Emilio Margáin Manautou, Las facultades de comprobación fiscal, México: Editorial Porrúa, 1999, p. 1.

18 Doricela Mabarak Cerecedo, op, cit., p. 231.

19 Emilio Margáin Manautou, op. cit., p. 6.

20 Eduardo García Máynez, Introducción al estudio del derecho, México: Editorial Porrúa, 2000 p. 295. 
propongo utilizar el esquema que plantea García ${ }^{21}$, que describe y distingue las consecuencias jurídicas desde tres tipos de sanción: el cumplimiento forzoso, la indemnización y las consecuencias punitivas.

En este entendido, la conducta ilícita por la cual se incumple una obligación tributaria sustantiva origina un daño a la hacienda pública, por lo tanto, como consecuencia jurídica, se exige al sujeto pasivo el cumplimiento del deber tributario sustantivo originalmente inobservado, es decir, cumplir con la cantidad monetaria que por concepto de obligación tributaria principal incumplió, en este supuesto estamos ante un cumplimiento forzoso.

Sin embargo, las consecuencias jurídicas ante el incumplimiento de un deber tributario sustantivo no se agotan solo con el cumplimiento forzoso. Además, se exige se compense al Estado por los daños y los perjuicios que se ocasionaron con el incumplimiento, mediante la imposición de una sanción de carácter indemnizatoria. En este sentido, el daño se traducen en la "pérdida o menoscabo sufrido en el patrimonio por la falta de cumplimiento de una obligación"22 y el perjuicio en "la privación de cualquier ganancia lícita que debería haberse obtenido con el cumplimiento de la obligación"23. Cabe señalar que en nuestro sistema tributario, el daño se compensa mediante la figura de la actualización y el perjuicio por medio de los recargos.

De tal guisa, que la figura de la actualización opera con motivo del daño que se le ha causado al fisco en virtud de la pérdida de valor del dinero por la inflación, es menester que referido tributo se actualice, a fin de dar un valor real al monto del mismo al momento de su pago, y reciba así un equivalente al que hubiera recibido de haberse cubierto en tiempo referida contribución, siendo esta equivalencia lo que la distingue del cumplimiento forzoso.

En lo que respecta al recargo, este se representa por una nueva afectación "carga o aumento de carga.- Nuevo cargo que se hace a alguien.- Valor que se agrega a otro o incremento de cualquier naturaleza sobre lo que se considera normal ${ }^{124}$, lo que se traduce en la cantidad adicional de dinero que el sujeto pasivo debe pagar al fisco a consecuencia del incumplimiento de enterarla dentro del plazo legal, con lo que se resarce al fisco de lo que lícitamente pudo haber obtenido si la obligación se hubiera cumplido dentro del plazo legal. Es incuestionable que a causa de esta dilación o mora el fisco sufrió un perjuicio por no haber pagado oportunamente citadas contribuciones y no permitir que el Estado hubiera satisfecho sus necesidades de gasto público en la misma oportunidad en las que se debió, de haber enterado en tiempo referido tributo. 
De tal manera que podemos afirmar que tanto en la actualización como en los recargos existe coincidencia, en cuanto a su origen, se dan por la falta de pago oportuno y en cuanto a su misma naturaleza, pues son consecuencias jurídicas indemnizatorias.

Sin embargo, en cuanto a su finalidad, existen diferencias claras, ya que mientras la figura de la actualización opera con motivo del daño que se le ha causado al fisco por no enterar dentro del plazo legal el deber tributario sustantivo que se adeuda, por tal razón y en virtud de la pérdida de valor del dinero por la inflación, es menester que referido tributo se actualice a fin de dar un valor real al monto de la misma al momento del pago para que el fisco reciba así un equivalente al que hubiera recibido de haberse cubierto en tiempo referida contribución. Por otro lado, en los recargos, su finalidad se da en el resarcimiento de un perjuicio causado al fisco federal por no haber pagado oportunamente citadas contribuciones $y$, por ende, no permitir que el Estado hubiera satisfecho sus necesidades de gasto público en la misma oportunidad en las que se debió de haber enterado referidos tributos.

Por lo que concierne a la consecuencia jurídica punitiva aplicada en el ámbito tributario, esta es una expresión del ejercicio de la potestad punitiva del Estado a través del procedimiento tributario sancionador. Sin embargo, su finalidad no es nada más causar un sufrimiento o castigo al infractor, sino que además esta aspira a una finalidad preventiva individual y general, intimidando al infractor para corregirlo y disuadirlo a evitar la repetición de la conducta ilícita, así como de una finalidad preventiva de orden general por la cual se ejemplifica a todos los habitantes de la sociedad con una amenaza de imposición de una pena para el caso de que alguno de sus miembros incurra en la comisión de algún ilícito de esta naturaleza, justificándose esta finalidad en la protección y salvaguarda de los bienes jurídicos más apremiante del grupo social como son los ingresos tributarios, y no con un propósito meramente recaudatorio.

\section{EL PROCEDIMIENTO TRIBUTARIO SANCIONADOR, EN EL CONTEXTO DEL EJERCICIO DE LA POTESTAD PUNITIVA DEL ESTADO, Y SUS PRINCIPIOS RECTORES}

El ejercicio del ius puniendi estatal en el ámbito tributario, como potestad punitiva exclusiva del Estado, se materializa por medio del derecho tributario sancionador, que como se acepta, junto con el derecho penal, constituyen las dos manifestaciones en que se desglosa esta potestad punitiva estatal, "cuando se imponen sanciones administrativas, igual que cuando los jueces imponen penas, se ejerce el ius puniendi del Estado. Se parte de que el Estado tiene un ius 
puniendi único que, según decida la ley, unas veces será ejercido por jueces y, otras, por autoridades administrativas ${ }^{\prime \prime 25}$.

Lo que se traduce en que el ejercicio del ius puniendi en el ámbito tributario, se da por medio de un procedimiento denominado tributario sancionador. Este se instituye como una serie de reglas y principios que limitan y regulan el ejercicio de esta faceta en que se desglosa la potestad punitiva estatal, con la finalidad de calificar a una conducta que incumple un deber tributario, como ilícita, y en aplicar su consecuencia jurídica punitiva, constituyendo

un régimen peculiar dentro del conjunto de la actividad de las administraciones públicas. Un régimen peculiar que es necesario, inspirado parcialmente en el derecho penal y el derecho procesal penal. Se caracteriza por ofrecer más garantías a los ciudadanos que las que estos tienen ante otros tipos de actuaciones administrativas: unas garantías parcialmente similares a aquellas que los ciudadanos tienen frente a las penas que imponen los jueces y tribunales. Esto justifica que, con muchas matizaciones y cautelas, se apliquen algunos principios penales a la actividad administrativa sancionadora ${ }^{26}$.

En consecuencia se reconoce al derecho penal como elemento integrador del derecho tributario sancionador, como acontece con las interpretaciones jurisprudenciales que el máximo Tribunal en México ${ }^{27}$, ha realizado admitiendo la aplicabilidad de los principios del derecho penal común al derecho tributario sancionador.

Entre estos principios en su aspecto sustantivo, como lo refiere Ortega ${ }^{28}$, se destacan, el de legalidad, el de reserva de la ley, el de tipicidad, el de no retroactividad de la ley, el de culpabilidad, el de personalidad de la pena, el de proporcionalidad de la pena, el de non bis in idem, el de prescripción; y respecto de los principios rectores del aspecto adjetivo de la potestad tributaria sancionadora, se ubican el principio de debido proceso, el de acceso a la justicia, el de presunción de inocencia, el de no autoincriminarse, el de caducidad y el de tutela jurisdiccional efectiva.

Manuel Rebollo Puig, Manuel Izquierdo Carrasco, Lucía Alarcón Sotomayor y AntoNio Bueno Armijo, "Panorama del derecho administrativo sancionador en España", Revista Estudios Socio-Jurídicos, vol. 7, n. ${ }^{\circ} 1,2005$, p. 24. Disponible en línea http://www.scielo.org. $\mathrm{co} / \mathrm{pdf} / \mathrm{esju} / \mathrm{v} 7 \mathrm{n} 1 / \mathrm{v} 7 \mathrm{n} 1 \mathrm{a} 01$.pdf.

26 Ibíd., pp. 23-24.

27 Es el caso de la Jurisprudencia P/J.99/2006, emitida por el Pleno de la Suprema Corte de la Nación, publicada en el Semanario Judicial de la Federación y su Gaceta, novena época, tomo XxIV, el 15 de abril de 2006, p. 1566. 


\section{LA TRAMITACIÓN SUIPEDITADA DEL PROCEDIMIENTO TRIBUTARIO SANCIONADOR EN LA LEGISLACIÓN MEXICANA}

Todo procedimiento administrativo constituye un camino por el cual transita la actividad de la Administración pública,

lo cual permite fincar un marco cierto para esa actuación al estar regulado legalmente a fin de hacer efectivo el Estado de derecho. No se trata solamente de fijar requisitos formales, de prever etapas concatenadas y dirigidas a producir resoluciones, sino dar cumplimiento a las finalidades jurídico-políticas de la administración pública y salvaguardar los derechos de los administrados ${ }^{29}$.

Es por lo que, a través del procedimiento administrativo, se ajusta el actuar de la Administración pública al orden jurídico, racionalizando su actividad destinada al ejercicio de estas potestades, evitando con ello "la arbitrariedad emboscada en la casuística y determinar los cauces precisos por los cuales se alcanzará la satisfacción de necesidades colectivas" ${ }^{\prime \prime 2}$.

Por lo anterior, se torna indispensable tomar en consideración que la finalidad que emana de cada una de las potestades que se ha otorgado al Estado afecta necesariamente los procedimientos a través de los cuales transitará el ejercicio de las mismas, de tal modo, que no se puede visualizar a los procedimientos que se llevan a cabo por parte de las autoridades tributarias, solo como una serie de formalidades o pasos de mera producción de actos administrativos con una finalidad meramente recaudatoria, ni tampoco se debe considerar solo la existencia de procedimientos administrativos unitarios, más bien, se debe reconocer la existencia de una diversidad de procedimientos que basados en la finalidad que persiguen, influyen en las consecuencias jurídicas que se producen y aplican, así como en las regulaciones y principios rectores tan disímbolos que impregnan a cada procedimiento.

En este contexto, el ejercicio de la potestad tributaria sancionadora, que se traduce en la valoración, calificación y aplicación de la consecuencia jurídica punitiva para sancionar un ilícito tributario, se da por medio del procedimiento tributario sancionador. Sin embargo, cabe señalar que el ejercicio de esta potestad punitiva en nuestra legislación tributaria ${ }^{31}$ se subsume y se subordina a un procedimiento de distinta naturaleza, como es el procedimiento de fiscalización

29 Miguel Pérez LóPEZ, "Los principios del procedimiento administrativo", Revista del Instituto de la Judicatura Federal, n. ${ }^{\circ}$ 5, 2009, p. 315. Disponible en línea https://revistascolaboracion. juridicas.unam.mx/index.php/judicatura/article/view/31692/28681.

30 Ibíd., p. 316.

31 El procedimiento de fiscalización tributaria, en específico el de visita domiciliaria y las infracciones tributarias, se regulan, respectivamente, en los artículos 42 (fracción III) al 47 y del 70 al 91-B en el Código Fiscal de la Federación. 
tributaria denominado "visita domiciliaria", dando como resultando un procedimiento tributario sancionador supeditado $y$, por consecuencia, carente de autonomía. De tal guisa que el ejercicio de esta potestad sancionadora punitiva se da dentro de un procedimiento unitario, donde se ejerce la competencia tributaria del Estado, con una finalidad tendiente a la vigilancia del cumplimiento de las obligaciones tributarias a cargo de los contribuyentes, es decir, tendiente a la comprobación e investigación de deberes tributarios a cargo del sujeto pasivo y la determinación de la intensidad monetaria de esos deberes tributarios, que es la finalidad de este procedimiento de fiscalización.

Al realizar un comparativo con la legislación española ${ }^{32}$, y en específico de las facultades fiscalizadoras referentes al procedimiento de inspección tributaria, que se asemeja al de visita domiciliaria en México, apreciamos que de igual manera la finalidad de este procedimiento lo es la comprobación de los elementos, actos o valoraciones presentados por el contribuyente en sus declaraciones, y la investigación para descubrir la existencia de hechos no conocidos por ella, es decir, descubrir hechos no declarados o declarados incorrectamente por el contribuyente.

De modo que la finalidad del procedimiento de fiscalización tributaria, se centra en la verificación del adecuado cumplimiento de las obligaciones tributarias por parte del sujeto pasivo de la relación tributaria y en su caso determinar un adeudo tributario, ante la necesidad de proteger la recaudación de recursos tributarios como medios para satisfacer los gastos públicos, y la aplicación de consecuencias jurídicas distintas, como es el cumplimiento forzoso donde se obliga al sujeto pasivo a dar cumplimiento con el deber sustantivo originalmente incumplido; además de indemnizar o reparar el daño que se causó al Estado mediante un equivalente que se realiza por medio de la actualización de las cantidades omitidas y del resarcimiento de los perjuicios causados al Estado mediante el pago de cantidades pecuniarias por concepto de recargos.

Por su parte, la finalidad del procedimiento tributario sancionador, como una de las facetas en que se ejerce la potestad punitiva del Estado, es muy distinta, en razón a que esta se da en la calificación de una conducta que ha incumplido un deber tributario y que por tanto se considera como ilícita, así como en la aplicación de consecuencias jurídicas de naturaleza punitiva,

un carácter represivo y se aplican no para remover la violación de la norma jurídica y restaurar las condiciones anteriores a la transgresión, sino con un propósito de punición al infractor y con el fin de intimidar en general a los sujetos a las mismas obligaciones, para inducirlos a evitar su violación, además de perseguir la corrección del infractor ${ }^{33}$.

32 Es el caso del artículo 145 de la Ley General Tributaria, donde se regula finalidad de las facultades fiscalizadoras en el procedimiento de inspección de tributos.

33 Margarita Lomelí Cerezo, Derecho fiscal represivo, México: Editorial Porrúa, 1998, p. 21. 
De esta manera, su finalidad no es la fiscalización o determinación de la obligación tributaria para proceder a su recaudación, sino que se centra en la represión y prevención de conductas tributarias merecedoras del reproche jurídico de la sociedad por medio de la imposición de una sanción de naturaleza punitiva que busca prevenir y castigar a los contribuyentes culpables de realizar actuaciones tipificadas en la ley como infracciones tributarias; es decir, su objeto se da en la calificación de una conducta omisa de un deber tributario como ilícita y en la aplicación de una consecuencia jurídica punitiva.

Es por tanto incorrecto, como acontece en nuestra legislación tributaria, que a la sanción económica punitiva se le considere accesorio de las contribuciones, y por tanto se le dé la misma naturaleza que al tributo. Esto es contradictorio, ya que la sanción punitiva, como hemos afirmado, se origina a causa de un ilícito ante el incumplimiento de un deber tributario y la contribución es un deber tributario de los ciudadanos de contribuir a los gastos públicos, por lo cual estamos de acuerdo con la afirmación que hace Lomelí Cerezo ${ }^{34}$, en el sentido de que las multas no se establecen con el propósito principal de aumentar los ingresos del Estado, sino para castigar las transgresiones a las disposiciones legales, por lo que se considera erróneo que estas se tomen como accesorios de las contribuciones y se permita su actualización, ya que se está castigando de forma reiterada en el tiempo la conducta ilícita sancionada, violentando con ello el principio de racionalidad de la pena.

En lo que concierne a los principios que rigen el ejercicio de la potestad fiscalizadora y el ejercicio de la potestad sancionadora punitiva del Estado, cabe señalar que, al otorgarse por medio de ley estas potestades en favor del Estado, se beneficia la seguridad jurídica en favor de los ciudadanos, pues se establecen límites al comportamiento del Estado. De igual manera, el establecimiento de estas potestades no significa una expresión opresiva e individual del gobernante hacia los ciudadanos, sino que atiende a una serie de expresiones sociales que se enmarcan dentro de un Estado de derecho en el que las actuaciones de las autoridades están reguladas y limitadas por normas jurídicas generales, a través de reglas y procedimientos legales mediante los cuales se ejercen estas potestades.

No obstante, el establecimiento en ley de estas limitantes "no es suficiente por sí sola ${ }_{i}$ es imprescindible, además, que la ley se ajuste a las normas y principios establecidos expresa o implícitamente en la Constitución ${ }^{135}{ }^{35}$, como ordenamiento normativo supremo del Estado, en las que como señala Bobbio ${ }^{36}$ 
"se establecen límites no solamente formales sino también materiales al poder político, bien representadas por las barreras de los derechos fundamentales".

En este marco, los principios rectores constituyen "criterios orientadores insertos en todo sistema jurídico" ${ }^{117}$, que dan certeza y seguridad jurídica al contribuyente. Elementos que constituyen valores "centrales en el contexto de la apología del Estado de derecho" ${ }^{138}$, y que de igual manera están influenciados por las finalidades de las potestades que se ejercen dentro del procedimiento tributario sancionador y del de fiscalización. De forma que en el ejercicio de las potestades otorgadas al Estado encontramos principios rectores que limitan estas actividades en el contexto de un Estado de derecho. El caso de la actividad fiscalizadora del Estado no es la excepción, pues encontramos principios rectores como el de legalidad tributaria, el cual ordena que no haya tributo sin una ley que lo establezca y que la determinación de estos deberes tributarios se debe apegar a la proporcionalidad y equidad, donde el ingreso tributario que se recaude se destine a satisfacer los gastos públicos del Estado.

El ejercicio de la potestad punitiva del Estado que se actualiza ante el incumplimiento de un deber tributario por medio del procedimiento tributario sancionador para punir esa conducta ilícita, se rige por principios tendientes a limitar el ejercicio de este ius puniendi. Dentro de estos se encuentran los principios de legalidad, de reserva de la ley, de tipicidad, de no retroactividad de la ley, de culpabilidad, de personalidad de la pena, de proporcionalidad de la pena, de non bis in idem y de prescripción; y respecto de los principios rectores del aspecto adjetivo de la potestad tributaria sancionadora, se ubican los principios de debido proceso, de acceso a la justicia, de presunción de inocencia, de no autoincriminarse, de caducidad y de tutela jurisdiccional efectiva.

Por consiguiente, con la subordinación del procedimiento tributario sancionador al procedimiento de fiscalización tributaria, se está desconociendo que la imposición de la sanción represiva en ejercicio de la potestad punitiva del Estado se da por el reproche a cierta conducta ilícita, y se rige por principios que se originan en el derecho penal. Los cuales, no aparecen claros en el ejercicio de esta potestad subordinada al procedimiento de visita domiciliaria, generando valoraciones o prejuicios distintos a la hora de aplicar la sanción punitiva. Esto debido a la finalidad que conlleva este procedimiento fiscalizador, donde se corre el peligro de alentar la práctica de imponer de plano la sanción punitiva o imponerla sobre la base de elementos y valoraciones obtenidos en el procedimiento de fiscalización, y no del ejercicio de la potestad tributaria sancionadora. Esta situación no da "certeza para el individuo de que su

38 Neil Maccormick, "Retórica y Estado de derecho", Isegoría, n. ${ }^{\circ} 21,1999$, p. 5. Disponible en línea https://www.ijf.cjf.gob.mx/cursosesp/2014/diploargulH/lecturas/Retórica\%20 y\%20Estado\%20de\%20Derecho.pdf. 
situación no será modificada más que por procedimientos legales previamente establecidos y, como consecuencia, no va a estar sometido a arbitrariedades" 39 , de forma tal que la "idea de seguridad jurídica implica la certeza, protección, firmeza y claridad de las normas jurídicas y su aplicación ${ }^{\prime \prime 4}$.

En torno al argumento que se presenta de cara un procedimiento unitario, en el cual se subordine al procedimiento sancionador tributario al procedimiento de fiscalización tributaria, a manera de ejemplo, en España ${ }^{41}$, se regula de forma separada estos dos procedimientos. El estrictamente tributario que contempla solo la fiscalización y determinación de la obligación tributaria, independiente del procedimiento punitivo sancionador ${ }_{i}$ especificándose en cada caso las formalidades, los principios y las consecuencias jurídicas que rigen a cada uno de estos procedimientos, lo que representa un claro ejemplo del respeto y reconocimiento a dos procedimientos distintos, donde se da el ejercicio separado y autónomo de dos potestades disímbolas como son la fiscalizadora y la sancionadora tributaria.

De manera que subordinar el procedimiento tributario sancionador a un procedimiento distinto, como es el procedimiento de fiscalización, no da certeza jurídica a los contribuyentes de que el ejercicio de la potestad punitiva sea imparcial y objetiva, es decir, que las valoraciones para aplicar la consecuencia jurídica punitiva se harán respetando la finalidad y los principios que rigen y limitan el ejercicio de la potestad punitiva; ya que, como se indicó, el procedimiento administrativo se constituye en un vehículo a través del cual transita la actividad del Estado, dando un marco de certeza al contribuyente de que se respetará la finalidad, las reglas, los principios y la valoración en la aplicación de las consecuencias jurídicas influenciadas en cada caso por la potestad del Estado que se está ejerciendo.

Con ello, se vulnera el derecho humano de seguridad jurídica, valor axiológico que es indispensable en un Estado de derecho, ya que "permite a los destinatarios del derecho calcular las consecuencias de su propio comportamiento y del prójimo" ${ }^{\prime \prime 2}$. En este caso, la regulación que se dé a la actuación del Estado será lo que haga la diferencia "entre la decisión caprichosa y autoritaria del más fuerte, y la decisión del poder ajustada al derecho, sometida y constreñida a los límites establecidos por la ley" ${ }^{\prime \prime 3}$.

Si lo que se pretende es el empleo utilitario de la potestad tributaria sancionadora y dar prioridad a la rapidez y eficacia de la fiscalización, en busca de

40 Rigoberto Gerardo Ortiz Treviño, La seguridad jurídica, México: Comisión Nacional de Derechos Humanos, 2004, p. 125. Disponible en línea http://200.33.14.34:1033/archivos/ pdfs/Jur_13.pdf. 
obtención de ingresos tributarios que beneficien a la comunidad estatal, parece que un procedimiento unitario seguirá siendo el adecuado. A pesar de ello, no se debe pasar por alto que "en una sociedad justa, las libertades básicas se dan por sentadas, y los derechos, asegurados por la justicia, no están sujetos a regateo político ni al cálculo de intereses sociales" ${ }^{\prime \prime 4}$, por lo que "la concepción del Estado moderno debe hallar sustentación suficiente, dentro del orden de la juridicidad, en el debido equilibrio entre el interés social y el de la persona humana, sin avasallamientos de unos que signifiquen perjuicios para el otro" ${ }^{\prime \prime 5}$.

\section{CONCLUSIONES}

Una vez analizados ambos procedimientos, tributario sancionador y de fiscalización tributaria, regulados en la legislación tributaria mexicana, y una vez analizadas las diversas finalidades, sanciones y principios rectores que se aplican y rigen a cada uno de ellos, se arriba a las siguientes conclusiones:

a. En a legislación tributaria mexicana no existe un procedimiento tributario sancionador independiente, pues este se subsume y se subordina en otro de distinta naturaleza con preponderancia en la recaudación de ingresos tributarios, como es el procedimiento de fiscalización denominado "de visita domiciliaria", resultando un procedimiento unitario donde conviven fines, principios rectores disímbolos y sanciones de naturaleza distinta.

b. En atención a la diversidad del procedimiento de fiscalización y del procedimiento tributario sancionador como vehículo en el que transita el ejercicio de la potestad respectiva y que influye en la finalidad que cada uno de estos procedimientos persigue, en la naturaleza de las sanciones que en ellos se imponen y en los principios que los rigen, no es posible hablar de un procedimiento unitario, pues se vulnera cada una de las características que impregnan al procedimiento tributario sancionador. En consecuencia, el contribuyente no tiene certeza de que serán respetadas las reglas y los principios que rigen a este procedimiento y que la valoración de la consecuencia jurídica punitiva será objetiva, y no influenciada por los datos de investigación y comprobación que tiene como objeto el procedimiento de fiscalización.

c. De esta forma, en un Estado de derecho y en pleno respeto al derecho humano de seguridad jurídica del contribuyente es pertinente que se de autonomía al procedimiento tributario sancionador del procedimiento de fiscalización. 


\section{BIBLIOGRAFÍA}

\section{LIBROS GENERALES Y ESPECIALIZADOS}

Álvarez Ledesma, Mario Ignacio. Introducción al estudio del derecho, México: Editorial McGraw Hill, 2015.

Bobbio, Norberto. Estado, gobierno y sociedad, México: Editorial Fondo de Cultura Económica, 2006.

De Pina, Rafael. Diccionario de derecho, México: Editorial Porrúa, 1983.

García Maynez, Eduardo. Introducción al estudio del derecho, México: Editorial Porrúa, 2000.

Habermas, Jürgen. Facticidad y validez, Madrid: Editorial Trotta, 2005.

Hallivis Pelayo, Manuel. Teoría general de la interpretación, México: Editorial Porrúa, 2009.

Jiménez González, Antonio. Curso de derecho tributario, México: Taxx Editores, 2014.

Lomelí Cerezo, Margarita. Derecho fiscal represivo, México: Editorial Porrúa, 1998.

Mabarak Cerecedo, Doricela. Derecho financiero público, México: Editorial McGraw Hill, 2007.

Margáin Manatou, Emilio. Las facultades de comprobación fiscal. México: Editorial Porrúa, 1999.

Ortega Maldonado, Juan Manuel. Primer curso de derecho tributario mexicano, México: Editorial Porrúa, 2004.

RaWls, John. Teoría de la justicia, México: Editorial Fondo de Cultura Económica, 2015.

Tarantino R., Jacinto. Las penalidades tributarias. Buenos Aires: Editorial Astrea, 1983.

\section{LIBROS ELECTRÓNICOS}

Ortega Maldonado, Juan Manuel. Justicia tributaria y derechos bumanos, México: Biblioteca Jurídica Virtual del Instituto de Investigaciones Jurídicas de la Universidad Nacional Autónoma de México, 2016. Disponible en línea https://archivos. juridicas.unam.mx/www/bjv/libros/9/4259/11.pdf.

Ortiz Treviño, Rigoberto Gerardo. La seguridad jurídica. Los derechos bumanos en la jurisprudencia mexicana, México: Comisión Nacional de Derechos Humanos, 2004. Disponible en línea http://200.33.14.34:1033/archivos/pdfs/Jur_13.pdf. 
Pauner Chulvi, Cristina. El deber constitucional de contribuir al sostenimiento de los gastos públicos. Castellón: Universitat Jaume I, 2000. Disponible en línea http://www. $\mathrm{tdx}$.cat/bitstream/handle/10803/10429/pauner.pdf? sequence $=1$.

Villegas, Héctor B., Curso de finanzas, derecho financiero y tributario, Buenos Aires: Ediciones Depalma, 2001. Disponible en línea https://es.scribd.com/doc/50090118/ Villegas-Hector-Curso-de-Finanzas-Derecho-Financiero-y-rio.

\section{ARTíCULOS ELECTRÓNICOS}

Domingues, José Marcos y Clemente Checa González. "Concepto de tributo: una perspectiva comparada. Brasil-España", Revista DIREITO GV 18, vol. 9, n. ${ }^{\circ} 2,2013$. Disponible en línea www.scielo.br/pdf/rdgv/v9n2/a09v9n2.pdf.

Maccormick, Neil. "Retórica y Estado de derecho", Isegoría, n. ${ }^{2}$ 21, 1999. Disponible en línea http://isegoria.revistas.csic.es/index.php/isegoria/article/view/74/74.

Pérez López, Miguel. "Los principios del procedimiento administrativo", Revista del Instituto de la Judicatura Federal, n. ${ }^{\circ}$ 5, 2009. Disponible en línea https://revistascolaboracion.juridicas.unam.mx/index.php/judicatura/article/view/31692/28681.

Rebollo Puig, Manuel, Manuel Izquierdo Carrasco, Lucía Alarcón Sotomayor y Antonio Bueno Armijo. "Panorama del derecho administrativo sancionador en España", Revista Estudios Socio-Jurídicos, vol. 7, n. ${ }^{\circ}$ 1, 2005. Disponible en línea https://dialnet.unirioja.es/descarga/articulo/2314908.pdf.

\section{JURISPRUDENCIA}

Suprema Corte de Justicia, tesis jurisprudencial P/J.99/2006, Semanario Judicial de la Federación y su Gaceta, novena época, tomo XXIV, 15 de abril de 2006. Disponible en línea http://sjf.scjn.gob.mx/sjfsist/Documentos/Tesis/1012/1012233.pdf. 